\title{
A New in-Plane Bending Test to Determine Flow Curves for Materials with Low Uniform Elongation
}

\author{
S. Naseem ${ }^{1}$ (D) E.S. Perdahcıoğlu ${ }^{1}$ - H.J.M. Geijselaers ${ }^{1}$ • A.H. van den Boogaard ${ }^{1}$
}

Received: 19 October 2019 / Accepted: 15 June 2020 / Published online: 17 August 2020

(C) The Author(s) 2020

\begin{abstract}
Background Flow curves can easily be obtained by uniaxial tensile tests, but strains are then limited by diffuse necking. For many applications, the flow stress must be known above this limit.

Objective The main objective of this paper is to obtain flow curves for material with low uniform elongation to relatively high strains compared to a uniaxial tensile test.

Method A novel in-plane sheet bending experiment and stress evaluation procedure is presented. The developed bending device can be mounted in a tensile test machine and can produce very high bending curvatures compared to previously proposed pure bending setups. The bending angle and curvature are obtained by image processing and the bending moment is calculated directly from the force measured from the tensile test machine and the bending angle. The moment-curvature relation is used to determine the uniaxial stress-strain relation using an analytical approach, without presuming any hardening model. The bending process and the analytical procedure are validated by a numerical simulation as well as by experiments.

Results The numerical validation shows good agreement between the stress-strain curve obtained from the bending process and that of the uniaxial input flow curve up to $12 \%$ strain. Experimentally the model is validated by comparing the stress-strain curve obtained from the bending test with the results directly obtained from a tensile test for mild steel. Good agreement is observed up to $12 \%$ strain. As an application example, bending tests were performed on a martensitic steel (MS) with low uniform strain (less than $3 \%)$. For this material, flow curves could be obtained up to relatively high strains $(\sim 12 \%)$, compared to a tensile test.

Conclusion This bending test setup allows to study materials with low uniform elongation up to significantly higher strains than are readily obtained in a tensile test.
\end{abstract}

Keywords Pure bending $\cdot$ High strain $\cdot$ Material testing $\cdot$ Martensitic steel $\cdot$ Flow curves

\section{Introduction}

The maximum strain in sheet metal forming processes is often higher than the uniform strain that can be achieved in a uniaxial tensile test. For simulation, the flow stress from a uniaxial tensile test is often extrapolated by fitting one of the available hardening laws. This introduces significant uncertainty in the simulation results. Especially, the prediction of stability of deformation is

Electronic supplementary material The online version of this article (https://doi.org/10.1007/s11340-020-00621-5) contains supplementary material, which is available to authorized users.

S. Naseem

s.naseem@utwente.nl

1 Faculty of Engineering Technology, University of Twente, P.O. Box 217, 7500 AE Enschede, The Netherlands highly affected by the actual hardening rate and therefore accurate flow stress data is required for the full strain range. Alternative sheet forming tests such as a bending test, a shear test and a bulge forming test are comparatively more stable than a tensile test and higher strains can be reached. There are two main challenges with these alternative tests. Firstly, for accurate and robust studies of material behavior it is necessary that the pure bending, simple shear and biaxial conditions are reliably and sufficiently homogeneously imposed during the experiments. Secondly, the output from the test must be measured accurately and then converted into the stress-strain relation of the material.

Conventional simple three point bending and four point bending tests can be easily performed in a universal tensile testing machine. The issue with these tests is the involvement of axial and transverse forces in the bending deformation. Additionally friction and local deformation under the contact points can be sources of errors. Bending setups have been 
developed where loads are applied without contact points which are often referred to in the underneath mentioned literature as pure bending, near pure bending or free bending setups. In this article, these setups will be referred to as pure bending setups. Compared to a three point or four point bending setup, these setups are complex and carry their own actuation and output measurement mechanisms.

Earliest pure bending setups were developed by [1, 2]. In [1], Perduijn and Hoogenboom developed a specially designed out of plane pure bending setup to study sheet material. Ben Zineb et al. [2] developed an out of plane pure bending setup for fatigue study of composite materials by bending to $2 \%$ strain. In their setup, by using sliding and pivot interfaces, a clamping system can be rotated by loading in a tensile machine. The rotation of the clamps is used to produce pure bending in the clamped beam sample. Weiss et al. [3] introduced a mechanism that can be used in a standard tensile test machine to perform out of plane pure bending. They showed good agreement of the moment-curvature results with a plane stress bending model for low curvature bending. The setup of [3] was used by Badr et al. in [4] to perform cyclic bending on Titanium alloy. The moment-curvature data along with uniaxial tension/compression experimental data and a finite element model were used to fit the parameters of the YLD20002D yield function incorporated with the homogenous anisotropic hardening (HAH) model. The above pure bending mechanism was limited to $1 \%$ strain in the outer most fibers [4]. Maeda et al. [5] developed an out of plane bending setup to investigate tension-compression asymmetry (TCA) for dual phase steel DP980. The experimental moment-curvature results from the bending setup were validated with the momentcurvature results iteratively calculated with pre-determined tension and compression data from a uniaxial test. They showed that if TCA is not taken into account the calculated moment-curvature results deviate from the measured one. Boers et al. [6] presented an out of plane bending setup to investigate the Bauschinger effect. The measured force and bend angle results were used to perform such an investigation. Kim et al. [7] developed an out of plane bending setup to study TCA in shape memory alloys. They measured the strain and moment-curvature relation. Cyclic bending tests were performed under $\sim 4 \%$ maximum deformation. A similar setup was presented by Sanchez et al. [8] to investigate Bauschinger effects in dual phase steels and aluminum alloys. The moment-strain relations were validated with those of numerically calculated moment-strain relations for the bending process with pre-determined tensile test data. In [9] Denk et al. proposed an in-plane bending setup for cyclic fatigue testing. The strains were measured using digital image correlation (DIC). From the forces the maximum linear stress is calculated using the flexure relation, which is used to generate $\mathrm{S}-\mathrm{N}$ curves. A miniaturized version of the pure bending setup was developed by Hoefnagels et al. [10]. The size of this setup allows for performing pure bending tests under a Scanning electron microscope (SEM).

Other than for sheet metals, pure bending devices have been developed and used for various materials, such as for composite materials by Ben Zineb et al. [2], weldments by $\mathrm{Bu} \&$ Gardner [11], flexible electronics by Hoefnagels et al. [12], micro electro-mechanical systems (MEMS) by Elhebeary \& Saif [13], micro thin sheet by Stölken \& Evans [14] and metal tubes by Guo et al. [15]. Alternative testing methods such as shear tests [16-18] and bulge tests [19-21] can also be used to obtain stress-strain data at high strains. These tests are in general complex in design. The shear test in particular requires efforts to perform the test without wrinkling of the specimen. Peirs et al. [22] developed a shear sample design which doesn't require an anti-buckling mechanism to perform a shear test. This sample design was used by Rahmaan et al. [23] to extract stress-strain data for DP600 steel and aluminium AA5182-O. An equivalent plastic work methodology is used to obtain the work hardening response to large strain levels using shear and tensile tests together. Another test procedure is the in-plane torsion test, which can be used to extract the material behavior, as in the work by Yin et al. [24].

To convert the measured output from these tests into stress-strain response of the material, inverse fitting methods are commonly used in literature [4, 7, 25-27]. These inverse fitting methods require accurate modeling of the processes with a predetermined hardening model and costly optimization loops. Another way to convert the moment-curvature relation directly into a stress-strain relationship is by using the analytical derivation of Nadai [28]. The derivation is explained in detail in Section 2. To the authors' knowledge this formulation has hardly been used in the sheet metal forming field. Two notable uses of such a derivation can be found in $[29,30]$. The aim of these two works was to measure the TCA in stress-strain behavior using a 4 point bending test. Both studies used rather low ductility material with TCA and strains up to $1 \%$, with an exception in [29] where copper was used also to investigate the pre-straining effect up to a strain of $5 \%$. In the overview above, most tests are out of plane bending tests up to a few percent of maximum strain. Some in-plane bending tests exist, but they are not pure bending tests and the transverse forces directly influence the deformation in the gauge area.

The aim of this paper is to demonstrate a simple and novel in-plane pure bending test setup to investigate large plastic deformation in metals. The proposed bending device is simple in design and can be used in a tensile test machine. Apart from that, the proposed bending setup has four advantages over the previously mentioned devices.

1. The in-plane bending allows for good mechanical stability up to high curvatures. 
2. The specimen is designed in such a way that it can be loaded using pin-hole interfaces without any clamping mechanism.

3. The specimen design for in-plane bending offers flexibility in fabrication of specimen beam dimensions. This flexibility allows for sizing of the specimen is such a way that it is not susceptible to out of plane buckling.

4. Through thickness inhomogeneities in the sheet metal will have negligible effect on an in-plane bending process, while in out of plane bending the effect is enhanced.

These advantages can be used to achieve high strains, which is a limitation in previously mentioned bending setups. The applied moment is calculated from the forces measured by the tensile test machine and the curvature is obtained from image processing of the specimen deformation respectively. The moment-curvature relation is directly converted into a stress-strain relationship by using the analytical derivation of Nadai [28].

With the new bending setup, high curvatures can be reached at which the validity of the analytical reverse calculation method becomes questionable. It is therefore necessary to perform a detailed validation to determine the range of applicability. Both numerical and experimental validations are performed. The numerical validation is performed with a $3 \mathrm{D}$ FEM model of the bending test. The stress-strain curve evaluated from the moment-curvature relation of the model is compared with the exactly known input flow curves of the simulation. In this way, the validity of the analytical equations can be checked for a 'perfect experiment'. The experimental validation is performed with a highly ductile mild steel to assess the practical applicability and limitations of the test for a material for which flow curves up to high strains are available.

To demonstrate the relevance of the test procedure, the proposed bending stage is used to evaluate the stress-strain curve for a very low ductility and high strength Martensitic Steel. In this class of steels the microstructure is almost fully martensitic with small islands of ferrite and bainite [31]. The application of these steels include rocker outer, side intrusion beams, bumper beams, and structural reinforcement components of the automotive body. In a uniaxial tensile test, the uniform strain is limited to $3 \%-5 \%$, while much higher strains are applied in forming operations, demonstrating the necessity for high-strain flow curves.

The content of this paper is described in sections as follows. In Section 2 the formulation for the conversion of moment-curvature into stress-strain relation is revisited. In Section 3 the design and development of the proposed bending setup is described. This is followed by the description of test method and evaluation of the output in Section 3. The validation and limitation of the testing and evaluation procedure is investigated using numerical modeling in Section 4. In
Section 5 various experimental results from the test are discussed, including experimental validation and application results. The discussion of the various sections is concluded in Section 6.

\section{Reverse Calculation of Stress-Strain from Moment-Curvature Curves}

For bending of a beam with a monotonically increasing moment, the stress and strain in the cross-section can be obtained from the moment-curvature diagram, under certain assumptions. The expression for the stress in the outer fibre from a known moment and curvature was described already in 1931 by Nadai [28, Chapter 23, p. 164]. The derivation by Nadai starts with assuming that the material has asymmetric tensioncompression flow stress. The equations are then derived for the tension and compression stress separately. Subsequently, the equations are simplified for symmetry in tension and compression. In order to derive an analytical equation, it is assumed that the cross section remains constant, the engineering strain follows a linear relation over the height, the neutral line is always in the middle of the cross section (Bernoulli hypothesis) and that the stress state is uniaxial. The implications of these assumptions are described below.

1. It is assumed that the material behaves symmetrically during plastic deformation under tension and compression. The implication is that for material with TCA the analytical procedure as presented here needs to be adapted.

2. It is assumed that the cross-section of the beam remains constant. This ignores the effect of anticlastic bending [32]. Due to distortion of the cross-section, the neutral line shifts towards the compression region. The shift of the neutral line will also cause previously compressed material to be loaded in tension. A brief discussion on the neutral line shift can be found in [33] for plane-strain bending. When the beam becomes highly curved, compressive stresses will develop in y-direction. Although these are an order lower than the tensile and compressive bending stresses, these will have an influence on the yield behavior of the material.

The implications described under 2 have negligible influence on the results for small curvatures, but the accuracy will decrease for higher curvatures. In Section 4, the influence of these simplifying assumptions will be investigated by a numerical example. For simplicity, the implication of point 1 is accepted as a limitation and only materials with a symmetric tension/compression behaviour are considered in this paper.

The derivation below follows a slightly different path than in [28]. Consider a beam with a constant rectangular cross section of height $h$ and width $b$ under pure bending such that 
the neutral line stays at $y=0$. The moment $M$ depends on the stress distribution $\sigma(\epsilon(\kappa, y))$ following:

$M=b \int_{-\frac{h}{2}}^{\frac{h}{2}} y \sigma(\epsilon(\kappa, y)) d y$

The engineering strain $\epsilon(\kappa, y)$ at any point $y$ in the cross section and curvature $\kappa$ are related by:

$$
\epsilon=\kappa y
$$

In Fig. 1, a typical stress and strain distribution over the height of the beam at a certain curvature $\kappa$ is shown.

It is important to note from Fig. 1, that $\sigma$ is only a function of $\epsilon$ and $\epsilon$ is function of $\kappa$ and $y$. We can take the derivative of Eq. (1) on both sides with respect to $\kappa$.

$\frac{d}{d \kappa} M=\frac{d}{d \kappa}\left(b \int_{-\frac{h}{2}}^{\frac{h}{2}} y \sigma(\epsilon(\kappa, y)) d y\right)$

The integral limits on the right hand side are not a function of $\kappa$, then according to Leibniz's rule:

$\frac{d M}{d \kappa}=b \int_{-h / 2}^{h / 2} \frac{d}{d \kappa}[y \sigma(\epsilon(\kappa, y))] d y$

Using the chain rule and realizing that $\kappa$ and $y$ are independent yields:

$$
\begin{aligned}
\frac{d M}{d \kappa} & =b \int_{-h / 2}^{h / 2} y \frac{d \sigma(\epsilon(\kappa, y))}{d \kappa} d y \\
& =b \int_{-h / 2}^{h / 2} y \frac{d \sigma}{d \epsilon(\kappa, y)} \frac{\partial \epsilon(\kappa, y)}{\partial \kappa} d y
\end{aligned}
$$

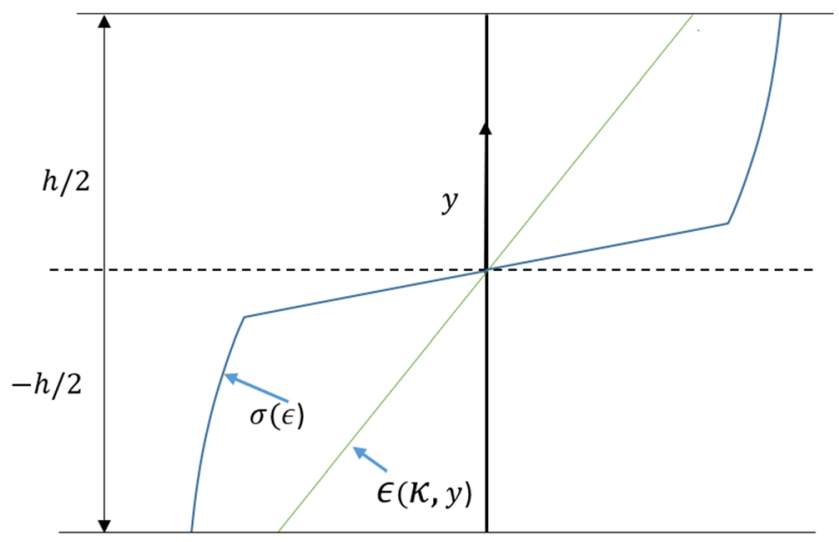

Fig. 1 Stress and strain distribution in beam at a certain curvature
From Eq. (2) follows $\left.\frac{\partial \epsilon}{\partial \kappa}\right|_{y}=y$, thus simplifying Eq. (5) to:

$$
\frac{d M}{d \kappa}=b \int_{-h / 2}^{h / 2} y^{2}\left(\frac{d \sigma}{d \epsilon(\kappa, y)}\right) d y
$$

For the bending case under consideration, according to Eq. (2), the derivative of stress with respect to strain can also be derived from the partial derivative of stress with respect to coordinate $y$ at constant curvature $\kappa$ :

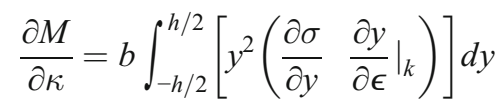

$\left.\frac{\partial y}{\partial \epsilon}\right|_{\kappa}=\frac{1}{\kappa}$ then leads to:

$\frac{\partial M}{\partial \kappa}=\frac{b}{\kappa} \int_{-h / 2}^{h / 2}\left[y^{2}\left(\frac{\partial \sigma}{\partial y}\right)\right] d y$

Eq. (8) can be integrated using Integration by parts:

$$
\frac{\partial M}{\partial \kappa}=\frac{b}{\kappa}\left(\left[y^{2} \sigma\right]_{-h / 2}^{h / 2}-\int_{-h / 2}^{h / 2} 2 y \sigma d y\right)
$$

and with $\int_{-h / 2}^{h / 2} y \sigma d y=\frac{M}{b}$

$$
\frac{\partial M}{\partial \kappa}=\frac{b}{\kappa}\left(\frac{1}{4} h^{2} \sigma(h / 2)-\frac{1}{4} h^{2} \sigma(-h / 2)-\frac{2 M}{b}\right)
$$

Based on the assumption that the material behaves symmetric in tension and compression $\sigma(-h / 2)=-\sigma(h / 2)$.

$$
\kappa \frac{\partial M}{\partial \kappa}=b\left(\frac{1}{2} h^{2} \sigma(h / 2)-\frac{2 M}{b}\right)
$$

such that:

$$
\sigma(h / 2)=\frac{2}{b h^{2}}\left(\kappa \frac{\partial M}{\partial \kappa}+2 M\right)
$$

The engineering strain $\epsilon_{l}$ at the outer most fibre $(h / 2)$ can be obtained from the curvature using:

$\epsilon(h / 2)=\kappa \frac{h}{2}$

The engineering strain can be converted to true strain in tension and compression $\varepsilon_{T}$ and $\varepsilon_{c}$, respectively, using: 


$$
\begin{aligned}
\varepsilon_{T}(h / 2) & =\ln (1+\epsilon(h / 2)) \text { and } \varepsilon_{c}(h / 2) \\
& =\ln (1-\epsilon(h / 2))
\end{aligned}
$$

It is now shown that the engineering strain is a first order approximation of the average of the $\varepsilon_{T}$ and $\varepsilon_{C}$. The average true strain can be written as:

$\varepsilon_{a v}(h / 2)=\frac{\varepsilon_{T}(h / 2)-\varepsilon_{c}(h / 2)}{2}$

Substituting Eq. (14) in Eq. (15):

$$
\begin{aligned}
\varepsilon_{a v}(h / 2) & =\frac{\ln (1+\epsilon(h / 2))-\ln (1-\epsilon(h / 2))}{2} \\
& =\frac{\ln \left(\frac{1+\epsilon(h / 2)}{1-\epsilon(h / 2)}\right)}{2}
\end{aligned}
$$

The term $\ln \left(\frac{1+\epsilon(h / 2)}{1-\epsilon(h / 2)}\right)$ can be approximated by a Taylor series expansion, resulting in:

$$
\begin{aligned}
\varepsilon_{a v}(h / 2)= & \frac{1}{2} \ln \left(\frac{1+\epsilon(h / 2)}{1-\epsilon(h / 2)}\right) \\
= & \epsilon(h / 2)+\frac{1}{3}(\epsilon(h / 2))^{3}+\frac{1}{5} \epsilon((h / 2))^{5} \\
& + \text { H.O.T }
\end{aligned}
$$

Putting the Taylor expansion results in Eq. (16), and neglecting the third and higher order terms gives:

$$
\varepsilon_{a v}(h / 2) \approx \epsilon(h / 2)
$$

Thus, the average true strain from Eq. (15) is coupled with the stress from Eq. (12) for comparison and validation purpose. Although several assumptions are made in the derivation of Eq. (12) and Eq. (15), in Section 4 and Section 5 it will be shown to give good results even for relatively high strains.

\section{Proposed Bending Setup}

A new test design is proposed that is able to perform pure bending in the plane of the sheet. This bending setup can be mounted in a tensile test machine. A special sample design is suggested for this process as illustrated in Fig. 2a). The sample has a reduced cross section in the middle that acts as a beam between two rectangular support sections. The support sections have holes for pins through which loads can be applied vertically. The pin-hole interface offers free rotation and are loaded as shown in Fig. 2. The applied boundary conditions will result in rigid rotation of the rectangular support sections causing pure bending in the beam as shown in Fig. 2 b). This in-plane bending of the sheet allows for a high curvature to height ratio, resulting in a high strain at the outer fiber.

\section{Design of the Bending Setup}

The detailed design of the physical setup to perform the above mentioned bending process is shown in Fig. 3. The setup which consists of two clamping units can be mounted in a tensile test machine. The setup has linear ball bearings to allow for free movement in X-direction, thus minimizing any axial forces. For free rotation in the hinges (pins), spherical rod ends with ball bearings are used. The model of the spherical rod end bearing used here is Kipp K0717.06. These bearings allows for self-alignment and offer very low friction in rotation.

\section{Sample Preparation and Testing}

The samples are prepared by laser cutting from metal plate. Typical sample dimensions can be seen in Fig. 4 and Table 1 . After laser cutting, the samples are spray painted in white. Next, the painted samples are engraved with an engraving laser using low power setting. The engraving is conducted such that it only affects the paint on the surface to produce contrast in the selected regions required for image processing. The engraving process marks several precise lines on the samples as shown in Fig. 4 b). These line segments at various sections of the beam can be used to calculate curvature at those sections.

Before testing of the sample, some masking is done on the sample using a black marker. Such physical masking makes image processing robust and easy in terms of tracking regions of interest. The sample is pinned in the bending setup. The pulling action from the tensile machine will cause bending of the beam section. A high definition camera (IDS UI-3590CP Rev. 2) and lens (Ricoh, FL-BC7528-9 M, 75 mm, 1") are used to record a video during deformation. The undeformed and deformed shape of the bending sample from a video recording of the test are shown in Fig. 5.

\section{Guidelines for Specimen Design}

The specimen design as presented in Fig. 4 is done in accordance with design constraints of the bending setup and to achieve sufficiently high strain at a uniaxial stress condition. Guidelines for three important dimensions necessary to achieve stable high strain under uniaxial stress conditions are given below.

1. Beam height $(h)$ : The beam height directly governs the maximum achievable strain in the outermost fibre. Therefore as a result, the higher the beam, the higher the achievable strain. The maximum height of the beam is 
Fig. 2 a) Schematic of the new bending setup with un-deformed sample. The pin-hole interface offers free rotation. b) Deformed sample

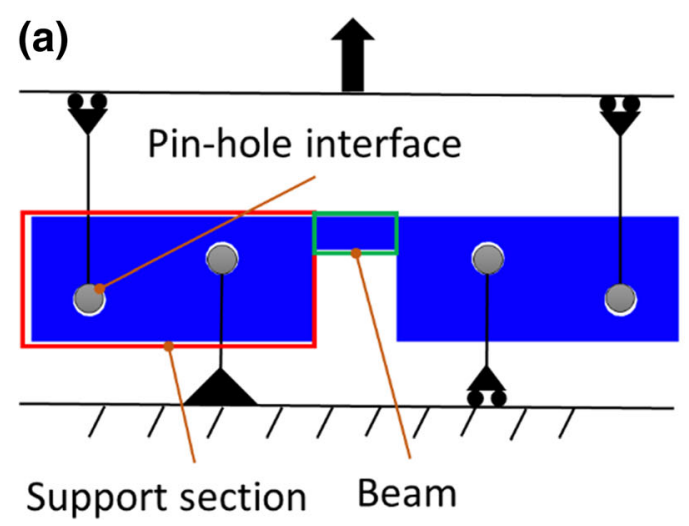

(b)

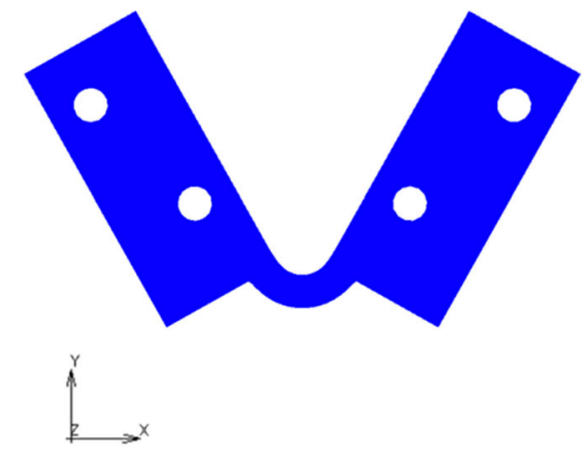

limited by the sensitivity of the bending process to out-ofplane buckling. From experience in this work, to avoid buckling, it is recommended to keep the ratio $h \leq 3 b$. Where $b$ is the sheet thickness. On the other hand the minimum value of $h$ is limited by the condition to achieve plane stress bending. This is essential to a uniaxial stress state at the outermost fibre of the beam. Based on the results of a finite element analysis, the recommended safe limit for a plane stress condition is $h>1.5 b$.

2. Beam length $(l)$ : The beam length directly governs the maximum achievable curvature. The shorter the beam length, the higher the maximum achievable curvature and thus, the higher the maximum achievable strain. The minimum length of the beam is limited due to the edge effect from the rectangular support section that will influence the stress state in adjacent regions of the beam. This limits the part of the beam in the middle that will undergo pure bending. Therefore, the beam should be long enough to produce a pure bending region that is large enough to measure the curvature with ease. From experience in this

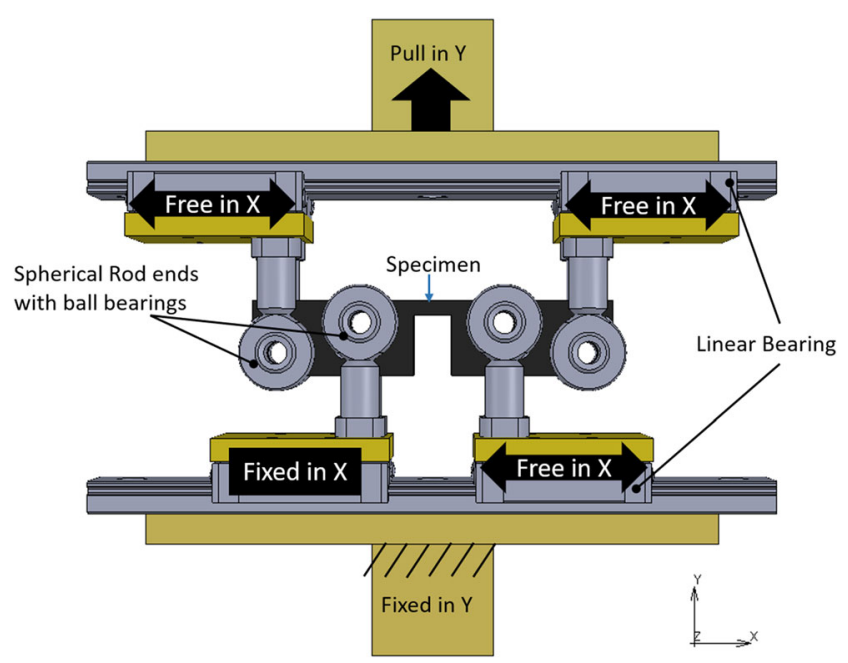

Fig. 3 Design of the bending setup with two clamping units including specimen. The setup can be mounted in a tensile test machine to perform pure bending work, as a design guideline a limit of $l>2 b$ for the beam length is recommended.

3. Another important dimension is the diameter of the pinhole interface and the position of the pins. This does not affect the maximum achievable strain, but should be sized in such a way that there is no plastic deformation at the hole.

Apart from the beam dimension the rest of the specimen dimensions are chosen in accordance with the dimensions of the bearings used in the bending setup. These dimensions are chosen such that a sufficient bending angle $\left(60^{\circ}\right)$ is achieved with the currently used bearings.

\section{Image Processing}

After the test is complete, the video recording is processed frame by frame in MATLAB R2017b to determine the curvature of the beam section and the rotation of the support sections.

\section{Curvature Calculation}

The curvature of the beam section is determined by processing the video recording of the experiment. Various strategies were tried for image processing of the video frames and the strategy with the most robust results is listed below.

1. The original grey scale image from the camera is first converted into a binary image.

2. A flood-fill operation on background pixels of the input binary image is performed to fill holes (islands of background pixels). In this operation holes are any background pixels which can't be reached by the filling operation from the outer boundary of the image.

3. The binary image is then cleaned around the edges. This is done by performing an erosion followed by dilation morphological operations using a specified morphological element. The element used in this case is a disk with radius 
Fig. 4 a) Laser cutting dimensions, $\mathrm{R}=1 \mathrm{~mm}$. b) Painted and engraved sample

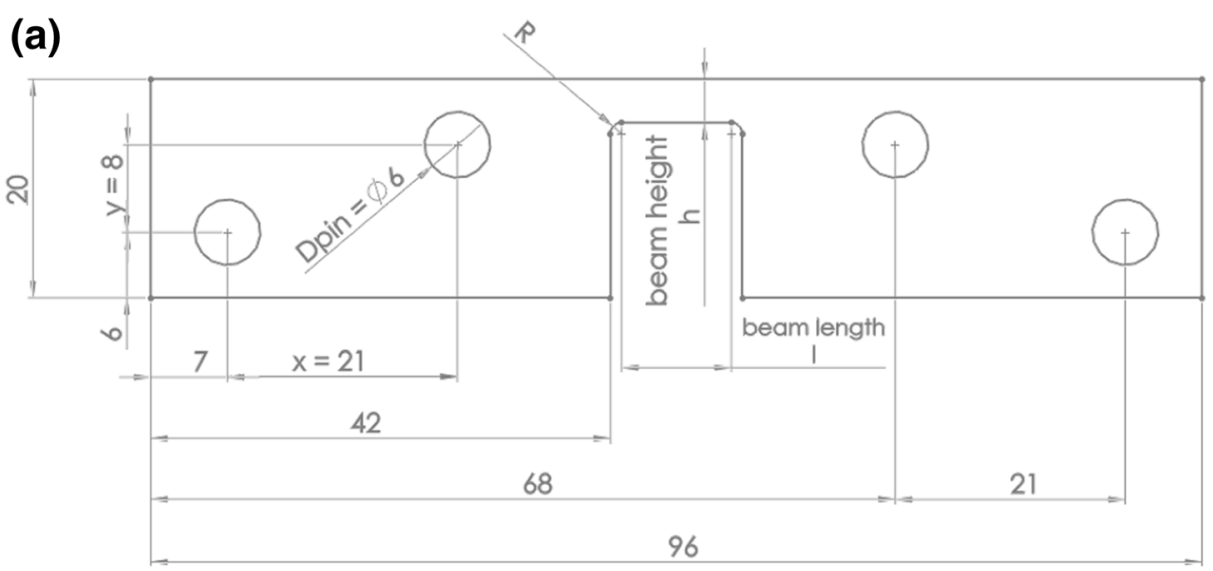

(b)

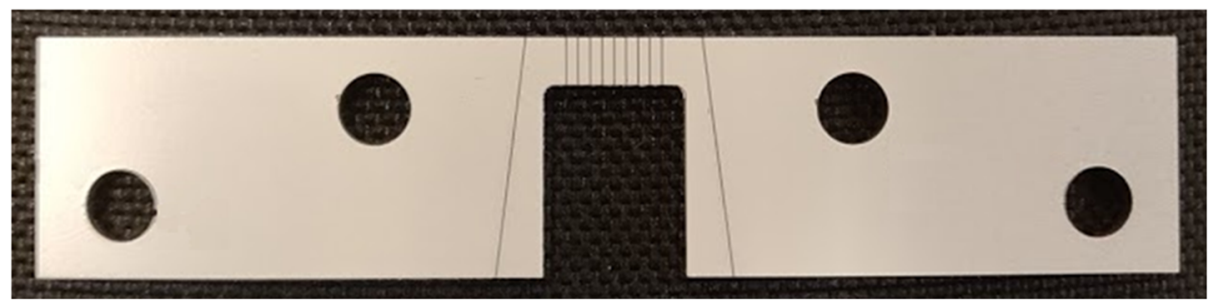

of 5 pixels. After that 2D mean filtering operation is performed to filter out any remaining noise on the edges.

4. The edges of all features (demarcation between black and white pixels) in the cleaned binary image are detected using the Canny method [34].

5. Boundaries are drawn along the detected edges for all the features. The procedure is based on the "boundaries" function given in [35] (see Fig. 6).

6. A calibration factor is calculated manually from the first frame with un-deformed specimen. The calibration factor is the ratio of the un-deformed beam height in $\mathrm{mm}$ to the height in pixel values. The collected boundaries are scaled to real world dimensions by multiplying with the calibration factor.

7. In step 5, a boundary is drawn around all features present in the image. Boundaries of the regions of interest are selected for further processing. The separated boundaries of the regions of interest are sorted based on their positions for orderly evaluation.

8. The detected boundaries represent the demarcation between black pixels in the engraved lines and the white pixels in the background. The angles for different beam sections are measured by fitting straight lines to the average of adjacent sides of the boundaries (see Fig. 7). The average is obtained by taking the mean of the coordinates of adjacent boundary points. The averaging of the boundaries gives robust results. The bending angle measurement $(\theta)$ is also illustrated in Fig. 7. The bending angle is required to calculate the bending moment (see Section 3.3.2).

Four curvature values are calculated from the outer to inner section along the beam length. For each section the initial length $l$ is measured from the first frame and angle $\phi$ for the fitted lines of Fig. 7 for each frame. For a beam-section $n$ where $n$ is from 1 to 4 , the curvature $\kappa_{n}$ at a particular time $t_{i}$ is given by:

$\kappa_{n}\left(t_{i}\right)=\frac{\phi_{n}\left(t_{i}\right)-\phi_{n}\left(t_{0}\right)}{l_{n}\left(t_{0}\right)}$

These four curvature values can be compared to see if the curvature is constant along the beam length.

\section{Moment Calculation}

The bending moment can be calculated from the measured forces and the position of the hinges. The force is measured

Table 1 Dimension of the specimen and the mesh size used in the simulation

\begin{tabular}{|c|c|c|c|c|c|c|}
\hline $\begin{array}{l}\text { Beam Length, } 1 \\
(\mathrm{~mm})\end{array}$ & $\begin{array}{l}\text { Beam Height, } \mathrm{h} \\
(\mathrm{mm})\end{array}$ & $\begin{array}{l}\text { Sheet thickness, b } \\
(\mathrm{mm})\end{array}$ & $\begin{array}{l}\mathrm{x} \\
(\mathrm{mm})\end{array}$ & $\begin{array}{l}\mathrm{y} \\
(\mathrm{mm})\end{array}$ & Mesh size for beam (mm) & $\begin{array}{l}\text { Elements through } \\
\text { thickness }\end{array}$ \\
\hline 10 & 4 & 2 & 21 & 8 & 0.25 & 6 \\
\hline
\end{tabular}


Fig. 5 Undeformed and

deformed shape of the bending sample. The images are from the video camera recording
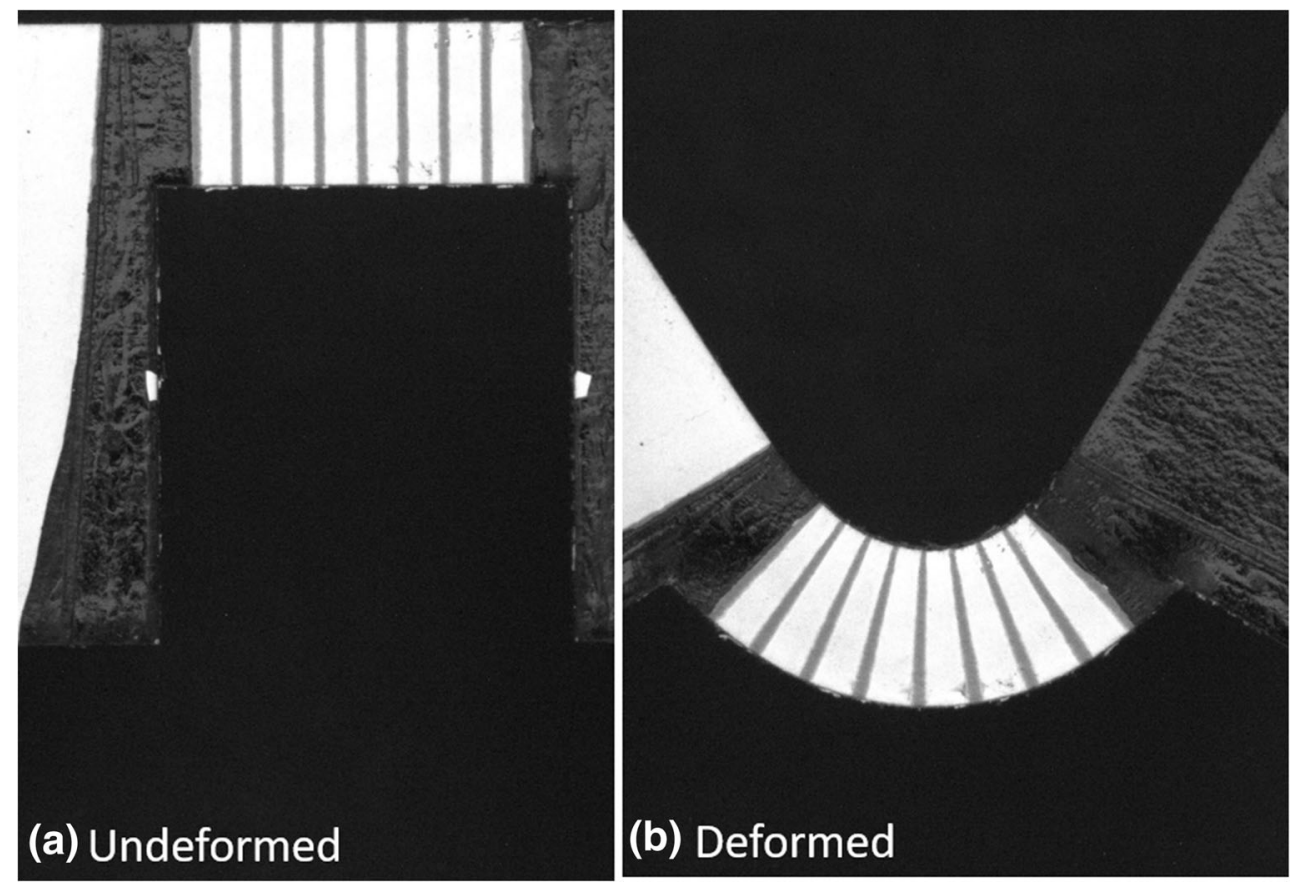

directly from the tensile test machine while the horizontal distance $d$ between hinged positions can be determined from the bending angle, which is calculated from image processing. The moment is calculated according to the illustration in Fig. 8.

The bending angle could also be calculated from the vertical displacement $v$ of the cross-head. Due to machine compliance, measurement of the bending angle from image

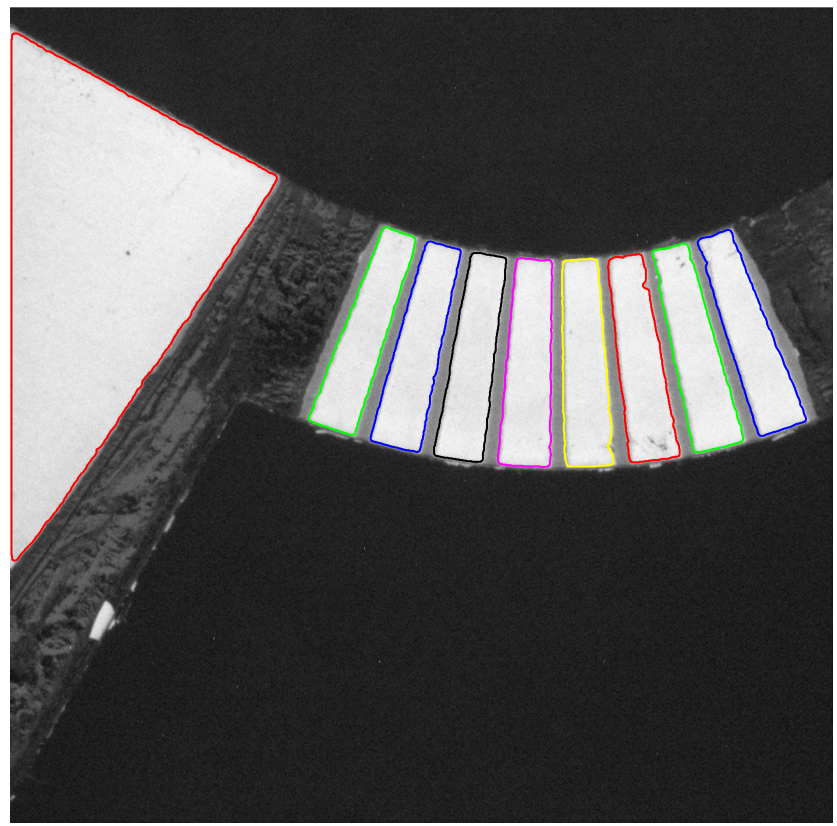

Fig. 6 The extracted boundaries using image processing are shown as an overlay on the image processing is more accurate than based on the cross-head displacement. According to Fig. 8, the moment is given by:

$M=F d$

where $F$ is half of the force measured by the transducer of the tensile test machine and $d=x \cos (\theta)+y \sin (\theta)$.

\section{Numerical Validation of Stress-Strain Calculation}

In this section, the equations for the reverse calculation of the stress-strain relation from the moment-curvature relation are validated by using a numerical model with exactly known hardening curve. The difference between the input hardening
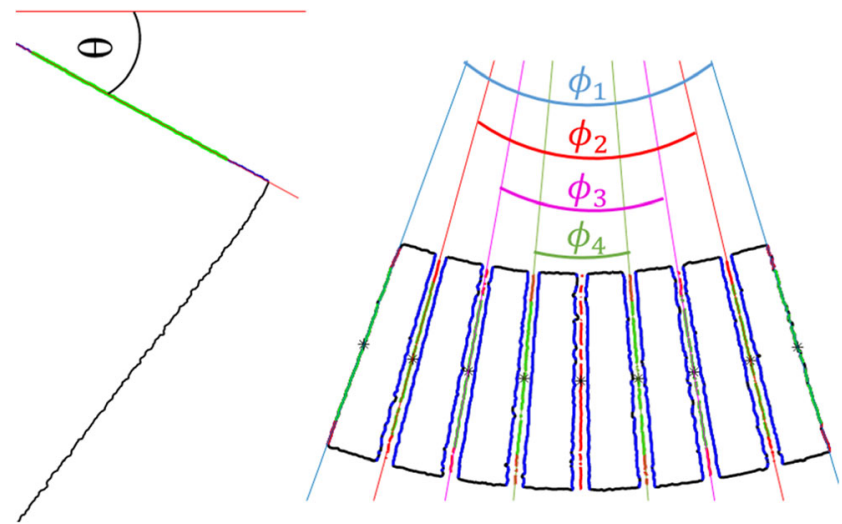

Fig. 7 Definition of angle of rotation $\theta$ and of curvature angles $\phi_{n}$ for various sections of the beam. This average represents each engraving line marked on the sample 
Fig. 8 Moment calculation for the bending test. Angle $\theta$ is measured from tracking the upper edge (red line) of the sample by image processing of the video (a)

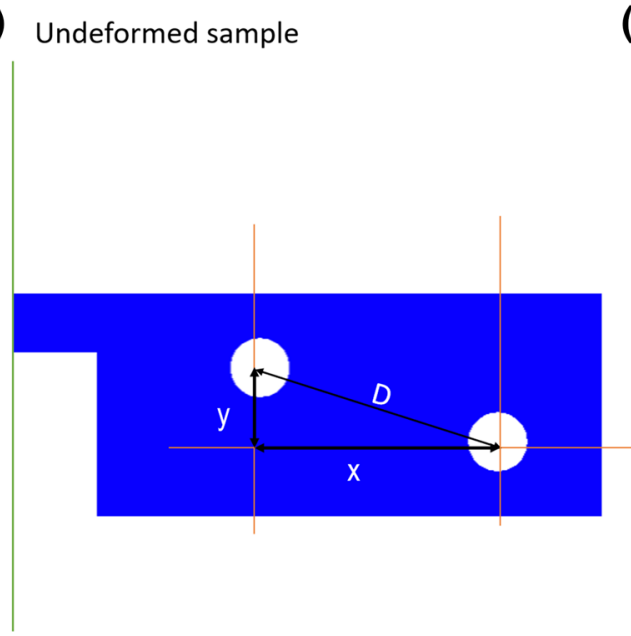

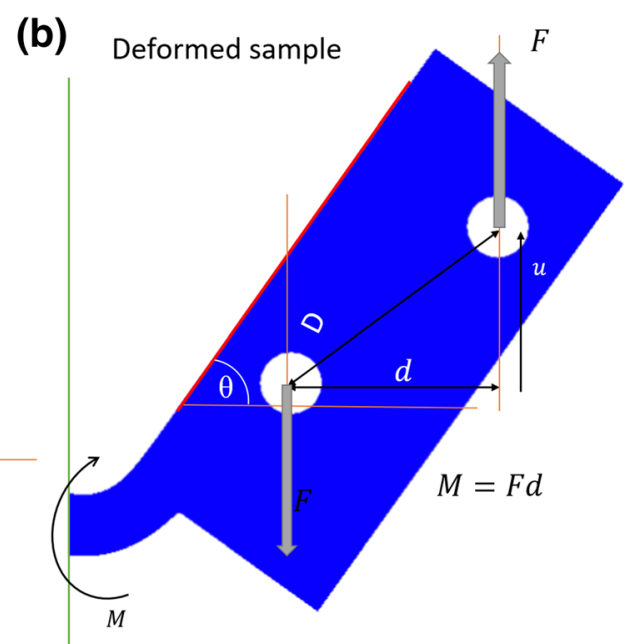

curve and the result from the analytical reverse calculation shows up to what level the assumptions that were made in the derivation are valid. The numerical simulation is performed with MSC.Marc 2017, where the beam section is modelled using linear 3D brick elements (element code 7) with enhanced assumed strain formulation to improve the accuracy in bending. Specifications of the specimen and mesh sizes are presented in Fig. 9 and Table 1 with beam length $10 \mathrm{~mm}$ beam height of $4 \mathrm{~mm}$ and sheet thickness of $2 \mathrm{~mm}$. No symmetry is used in the model for this initial analysis. Frictionless contact is used for the pin-hole interface. The simulation is performed with a von Mises yield function. Isotropic hardening behaviour is applied, using the Swift hardening law:

$\sigma_{f}=K\left(\varepsilon_{o}+\varepsilon_{p}\right)^{n}$

With $K, \varepsilon_{o}$ and $n$ material parameters, equal to $550.8 \mathrm{MPa}$, 0.01024 and 0.2163 respectively. These are representative values for mild steel.

Curvature and moment are calculated by processing the nodal data of the simulation output files in MATLAB and then using the procedure described in Sections 3.3.1 and 3.3.2. The calculated moment and curvature are used in Eq. (12) to determine the stress. Eq. (14) and (15) are used to determine the average true strain. The stress-strain curve achieved by using the reverse analytical calculation is then compared to the input flow stress curve. The comparison is shown here for a maximum curvature of $0.11 \mathrm{~mm}^{-1}$ with true strains up to $23 \%$ in the outermost fibres Fig. 10. The axial component of stress and strain is also separately evaluated at the nodal position in the outermost tension and outermost compression fibre of the beam section. The comparison shows that the reverse calculation is in good agreement until $\sim 12 \%$ strain. The deviation becomes significant after $15 \%$ strain. Thus, the assumptions that were made in Section 2, leading to the reverse analytical calculation are acceptable for strains up to $12 \%$.

The equivalent plastic strain, axial strain and radial stress $\sigma_{22}$ are plotted in Fig. 11 at $12 \%$ and $42 \%$ maximum strain in the beam. It can be seen that the deviation between the linear engineering strain and nonlinear true strain is small for the case of $12 \%$ maximum strain. Also at $12 \%$ of strain, the maximum value of the stress $\sigma_{22}$ is small compared to the maximum value of axial stress $\sigma_{11}$ in Fig. 10. At a maximum strain of $42 \%, \sigma_{22}$ becomes significant. Therefore, at high strain the stress-strain curve derived from the reverse analytical calculation deviates from the input flow curve for strains above $12 \%$. It should be noted that the limitation for accurate evaluation of stress-strain relations to $12 \%$ strain is due to the assumptions made in the analytical conversion. With a

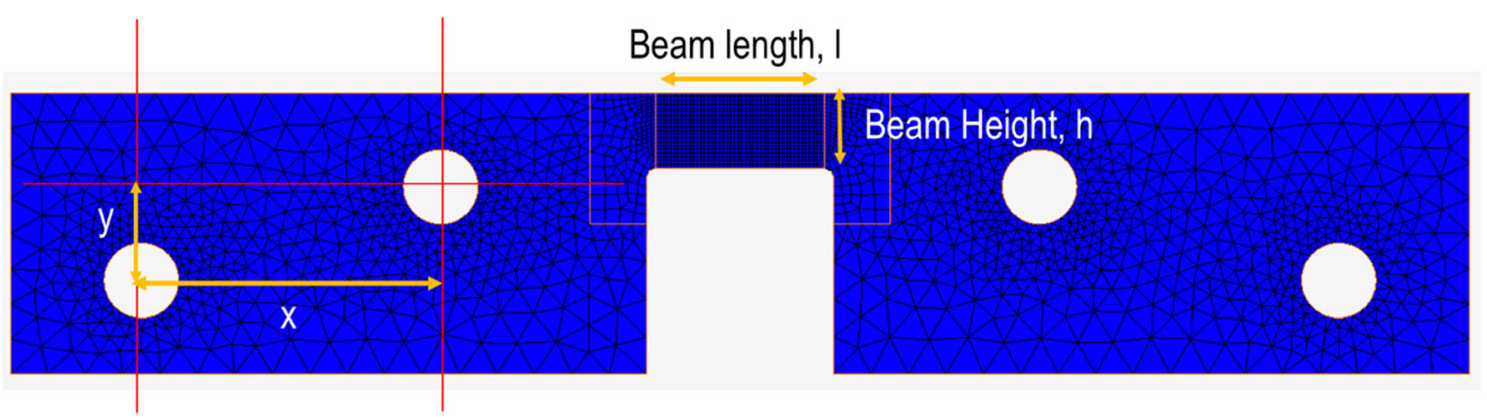

Fig. 9 Dimensions of the simulation specimen, and illustration of the mesh (3D) used 


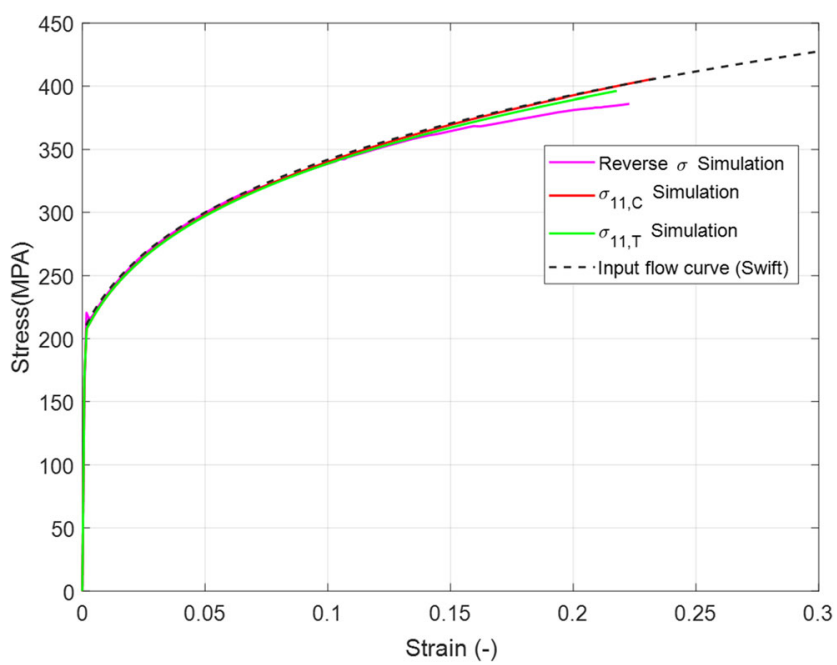

Fig. 10 Comparison of input flow stress from simulation with reverse calculation of stress from moment-curvature of simulation. The agreement of the axial component of the outer most compression (red) and tension (green) fibre stress is also shown

numerical evaluation framework where all phenomena of the pure bending process are properly taken into account, the stress-strain relation can be obtained up to higher strains, still without assuming a pre-defined hardening formula. It should be noted that even for material with symmetric tension and compression behaviour, the engineering strains are only symmetric for low curvatures. At higher curvature due to shift of the zero strain position, the engineering strains become nonsymmetric. If the material behaviour has TCA, the engineering strains are asymmetric in tension and compression from the beginning. In these cases, it is necessary to measure the strains in the outermost fibres of the beam or measure curvature and one of the outermost fibre strain. For the case of asymmetric tension and compression strains the curvature is given by.

$\kappa=\frac{\left(\epsilon_{T}-\epsilon_{C}\right)}{h}$

where $\epsilon_{T}$ and $\epsilon_{C}$ are the engineering strains of the outermost fibres in tension and compression, respectively. The equation for reverse calculation of stress for the asymmetric stressstrain material can be found in [28]. The application of these equations has already been demonstrated by $[29,30]$ for four point bending, but only for strains in a range of $1-5 \%$.

\section{Experimental Validation and Application of the New Bending Setup}

Experiments have been performed with the new bending setup according to the methodology described in Section 3. Experiments are divided into two categories: validation and application. In the experimental validation, a very ductile mild steel is used for which the stress-strain curve can also be determined up to high strain in a tensile test. The curve from the reverse analytical calculation is compared with the direct tensile experiment. The difference with the numerical validation is that now also measurement uncertainties are included. In the experimental application a low-ductility material is used with less than $3 \%$ uniform strain in a tensile test.

\section{Validation Experiments}

The validation experiments are performed on a ductile mild steel. High ductility of the steel allows for high uniform strains. The tensile test results for $2 \mathrm{~mm}$ thick mild steel are given in Fig. 14. which are used to compare with and validate the results of the proposed bending test using the reverse analytical calculation. The bending tests are performed for $2 \mathrm{~mm}$ thick mild steel with specimens cut in the plane of the sheet according to the dimensions given in Fig. 4 a) and Table 1 . with beam height of $4 \mathrm{~mm}$.

First the result of the curvature measured at different sections of the beam from the engraved line segments is shown in Fig. 12. For comparison, the curvature calculated from the bending angle $(\theta)$ is also plotted. The comparison shows that the measured curvatures along the beam between various line segments coincide in the beginning. First the curvature of the outermost line segments $\left(\kappa_{1}\right)$ starts to deviate, because it is
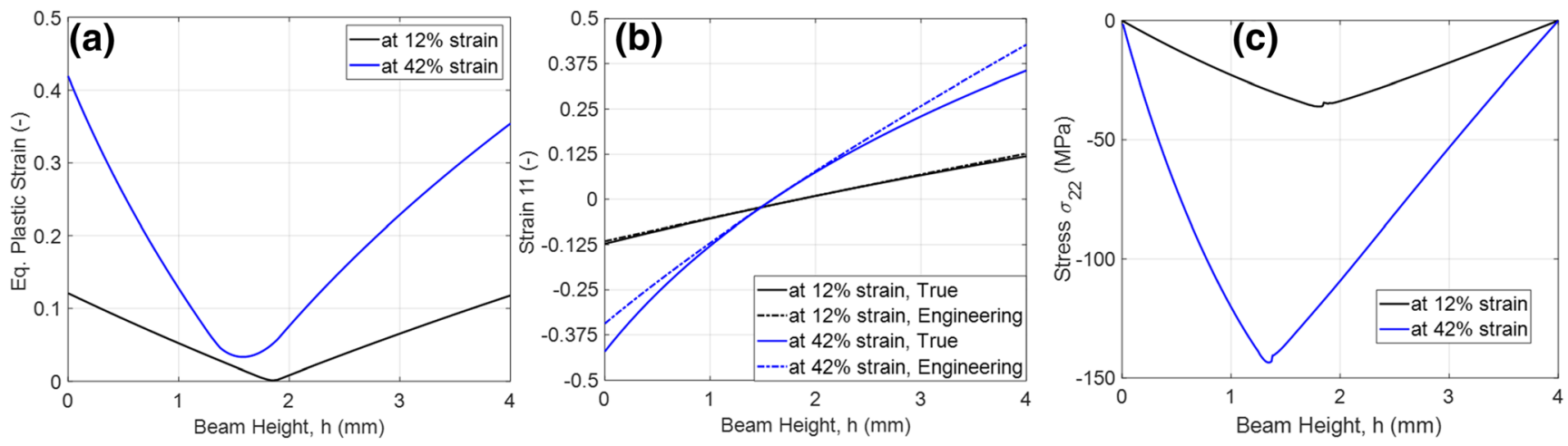

Fig. 11 Plots of the a) Equivalent plastic strain, b) Axial Strain and c) Stress $\sigma_{22}$ at $12 \%$ and $42 \%$ strain during the bending FEM simulation 


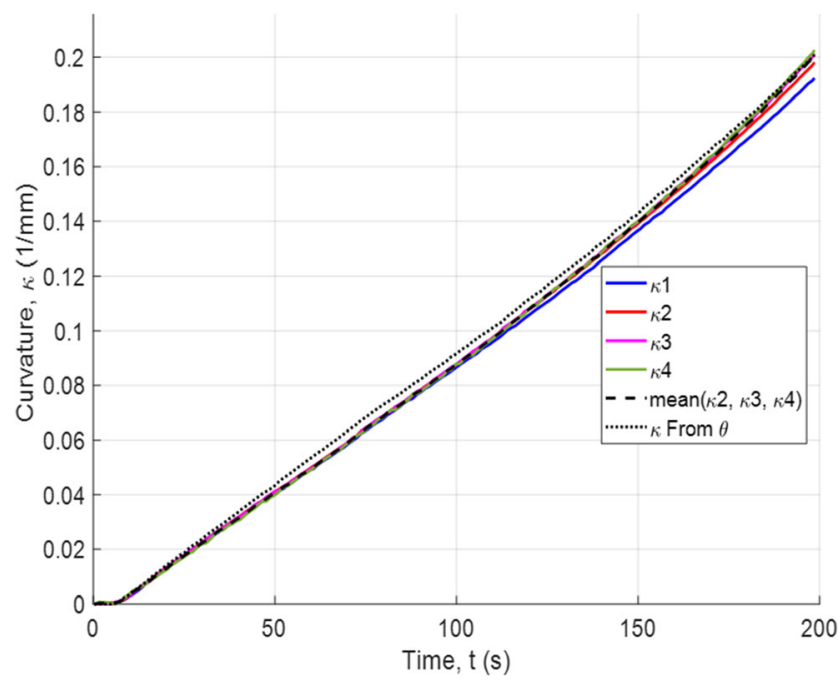

Fig. 12 Comparison plots of the curvature measured at different sections along the length of the beam

most influenced by the boundary to the support section. Curvature of the inner 3 line segments are on top of each other, indicating a constant curvature over a large part of the beam section. For evaluation purpose the mean of the curvature calculated from the inner 3 lines is used.

A typical force-displacement curve from the tensile machine for the bending process is shown in Fig. 13a). Using Eq. (20), the bending moment can be calculated from the forces measured by the tensile test machine. The momentcurvature relations are given in Fig. 13b). The momentcurvature relation can be used in Eq. (12) to analytically reverse calculate the stress-strain relation. The calculation involves the derivative of the moment with respect to curvature. For good accuracy, it is necessary to smooth the momentcurvature curve before taking the derivative. The smoothing is performed using a Savitzky-Golay filter. This method uses a polynomial to smooth over a specified moving-window of the data. To avoid an offset in elastic-plastic transition region an adaptive moving window scheme is used. In the elastic region, a small window size of 3 data points is used and a large window of 151 data points is used for the plastic region of

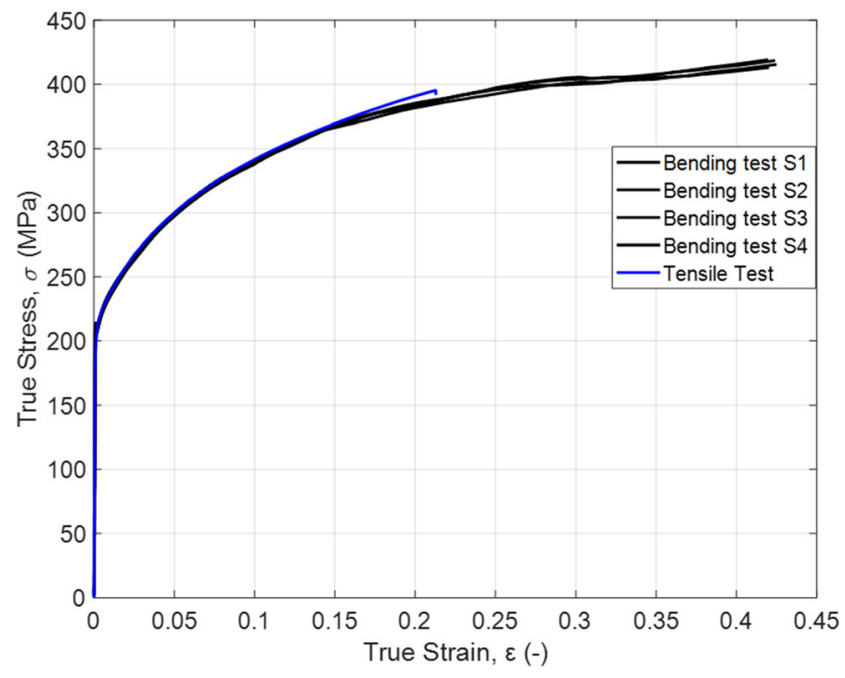

Fig. 14 Comparison of the stress-strain curves from the bending process with the stress-strain curves from tensile tests for mild steel

the curve. The smoothing window linearly increases from small to large in the transition region of the curve. This allows for optimal smoothing without any offset from the original curve with $\mathrm{R}^{2}$ values as high as 0.9993 . The smoothing result is shown in Fig. 13b). For better comparison the derivative of the smoothed and non-smoothed moment data is also plotted in Fig. 13c). The high $\mathrm{R}^{2}$ values and the comparison of the smoothed and non-smoothed data shows, that the smoothing process will have negligible systematic effects on the results.

The results for the reverse calculation of the stress-strain curves for 4 samples is compared to that of the uniaxial tensile stress-strain results in Fig. 14. The comparison shows a good agreement between the bending and tensile test result up to $\sim 12 \%$ strain and clearly deviates above $15 \%$ strain. The result of the 4 samples shows very good repeatability of the bending test. The experimental validation shows that it is feasible to determine the stress-strain curve of a material from the presented bending test using the analytical reverse calculation with sufficient accuracy over the complete range from 0 to $12 \%$ strain. For higher strains, the numerical validation
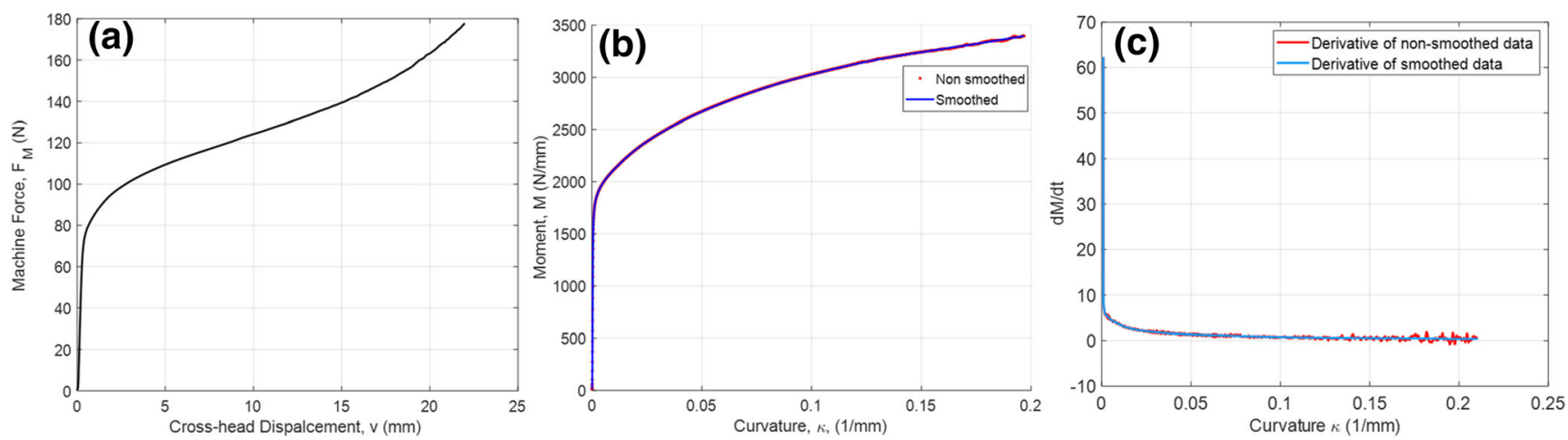

Fig. 13 a) Typical force-displacement curve for the bending process. b) Smoothing of the moment-curvature curve. c) Comparison of the derivative of smoothed and non-smoothed data 
Table 2 Chemical composition for Docol $1400 \mathrm{~m}$ (Mass fraction of alloying elements in percent)

\begin{tabular}{lllllll}
\hline $\mathrm{C}$ & $\mathrm{Si}$ & $\mathrm{Mn}$ & $\mathrm{P}$ & $\mathrm{S}$ & $\mathrm{Al}$ & $\mathrm{Nb}+\mathrm{Ti}$ \\
\hline 0.2 & 0.4 & 1.6 & 0.02 & 0.01 & 0.015 & 0.1 \\
\hline
\end{tabular}

showed already that the assumptions made for the analytical reverse calculation are no longer valid.

In the bending experiments with the proposed setup, a maximum strain of $42 \%$ could be obtained. To determine a reliable stress-strain relation up to this high strain, however, a more advanced reverse calculation procedure must be developed.

\section{Application Experiments}

The results of the numerical and experimental validation discussed above show that the new bending test and the reverse calculation of the stress-strain relation can be used for strain ranges up to $\sim 12 \%$. As mentioned before, the potential application of the new bending setup is to determine stress-strain curves for materials with low uniform strain. As an example, the hardening behaviour of SSAB Docol $1400 \mathrm{~m}$ martensitic steel is investigated, where uniaxial tensile tests reach very limited elongation [31,36]. A study on the microstructural analysis of Docol $1400 \mathrm{~m}$ can be found in [37]. The chemical composition of the steel according to the supplier is given in Table 2.

For this study $1 \mathrm{~mm}$ thick Docol $1400 \mathrm{~m}$ martensitic steel is used. The samples are cut according to the dimensions provided in Table 1 but with beam heights of $3 \mathrm{~mm}$. Since the sheet thickness is $1 \mathrm{~mm}$ for this material, a beam height of $3 \mathrm{~mm}$ is used, because a $4 \mathrm{~mm}$ high beam showed out of plane buckling.

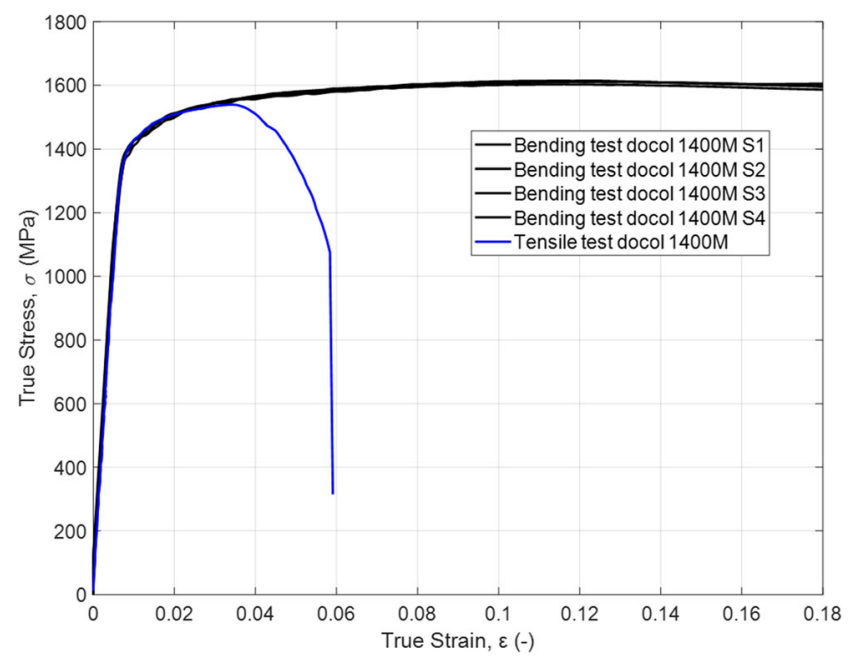

Fig. 16 Comparison of the stress-strain behaviour of Docol $1400 \mathrm{~m}$ steel from a tensile test and from bending tests

A typical bending moment-curvature relation for this material is shown in Fig. 15. It can be seen that the momentcurvature relation shows softening behaviour after a curvature value of $0.15 \mathrm{~mm}^{-1}$. This softening can be attributed to local flattening (necking) in the tensile outer region. Micro-cracks are observed after the test on the tension side of the beam. This strain region is of no interest, as it is already beyond the accurate strain range of $\sim 12 \%$ (at curvature of $0.08 \mathrm{~mm}^{-1}$ ) for which the current inverse formulation can evaluate the stressstrain relations as shown in Fig. 15b).

Stress-strain curves evaluated using the analytical reverse calculation for four samples are compared with curves from tensile tests performed on the material in Fig. 16. The tensile test of the material shows necking at a strain of 3\% and the specimen fails at a strain below $5 \%$. On the other hand the bending test shows very high deformation stability for this material. As discussed in the previous sections, the results are accurate up to $12 \%$ strain. Furthermore, the bending test shows very good repeatability for the results of the four samples within the valid strain range.
Fig. 15 a) Typical forcedisplacement curve and $b$ ) Moment-curvature curve for Docol $1400 \mathrm{~m}$ steel
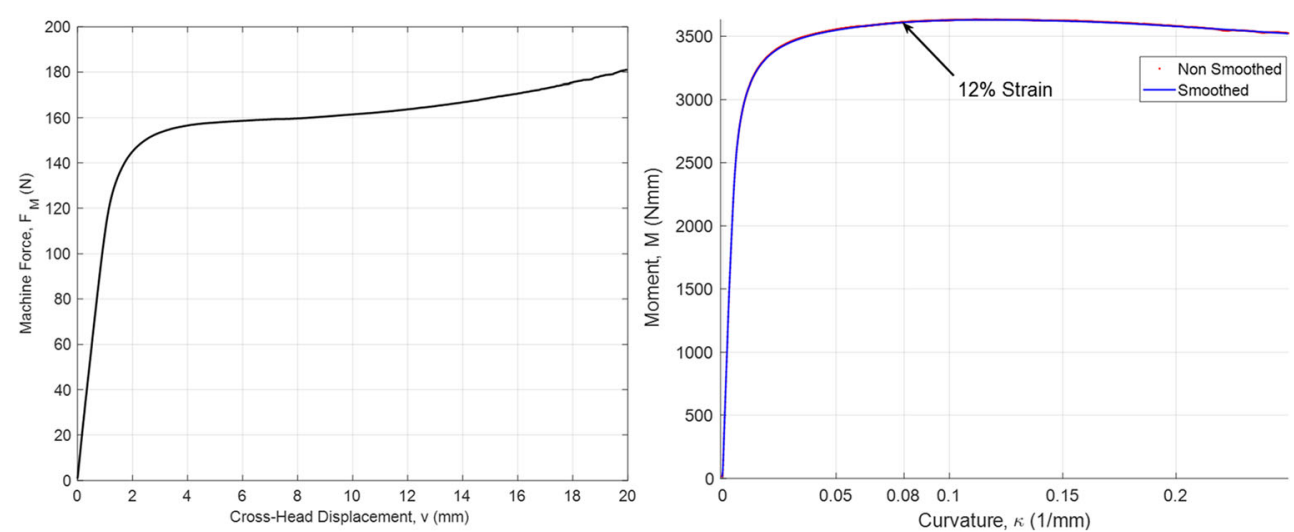
It would not be possible to observe high strain hardening behaviour of the above steel with a simple tensile test. The results show that the proposed bending setup and analytical reverse calculation can be used for materials with a low uniform strain in a uniaxial tensile test. The bending setup allows to study these materials at significantly higher strains.

\section{Conclusions}

After the numerical and experimental validation and the first application to a low ductility material, the following conclusions can be drawn.

1. A novel experimental bending setup is presented in this paper. The bending setup allows for high curvature inplane pure bending of sheet specimens. In the proposed setup the moment is evaluated directly from the forces measured by the tensile machine and the bending angle and the curvature is evaluated by image processing.

2. An analytical method for reverse calculation of the stressstrain relation from the moment-curvature relation is applied and validated with a numerical simulation model as well as with experimental results.

3. The numerical validation shows that the method allows for good agreement up to $\sim 12 \%$ of strains. In experiments strains up to $42 \%$ were achieved for mild steel, almost twice as much as in a uniaxial tensile test.

4. Also in validation experiments agreement up to $12 \%$ strain was observed with tensile test results. For accurate evaluation of stresses at higher strains, a numerical procedure must be developed.

5. For demonstration purposes, the bending setup was used for a martensitic steel, Docol $1400 \mathrm{~m}$. It contains a very high amount of martensite and shows a very low uniform strain. The bending test showed very high deformation stability for this steel with strains up to $20 \%$. Stressstrain curves up to $12 \%$ can be determined accurately with the newly proposed bending setup. This is not possible with standard tensile tests as the specimen necks at a strain of $3 \%$.

Overall, the bending setup offers a simple and unique solution for in-plane pure bending of sheet material. The moment-curvature measurement from this setup can be used to study hardening behaviour up to relatively high strain.

Funding Part of this work was executed in the research program financed by the Province of Fryslân under project number 01111010.

\section{Compliance with Ethical Standards}

The authors declare that they have no conflict of interest.
Open Access This article is licensed under a Creative Commons Attribution 4.0 International License, which permits use, sharing, adaptation, distribution and reproduction in any medium or format, as long as you give appropriate credit to the original author(s) and the source, provide a link to the Creative Commons licence, and indicate if changes were made. The images or other third party material in this article are included in the article's Creative Commons licence, unless indicated otherwise in a credit line to the material. If material is not included in the article's Creative Commons licence and your intended use is not permitted by statutory regulation or exceeds the permitted use, you will need to obtain permission directly from the copyright holder. To view a copy of this licence, visit http://creativecommons.org/licenses/by/4.0/.

\section{References}

1. Perduijn AB, Hoogenboom SM (1995) The pure bending of sheet. J Mater Process Tech 51(1-4):274-295. https://doi.org/10.1016/ 0924-0136(94)01596-S

2. Ben Zineb T, Sedrakian A, Billoet JL (2003) An original pure bending device with large displacements and rotations for static and fatigue tests of composite structures. Compos Part B 34(5): 447-458. https://doi.org/10.1016/S1359-8368(03)00017-9

3. Weiss, M., Wolfkamp, H., Rolfe, B.F., Hodgson, P.D., Hemmerich, E. (2009). Measurement of bending properties in strip for roll forming. In international deep drawing research group, pages 521-532

4. Badr O, Rolfe B, Zhang P, Weiss M (2017) International journal of mechanical sciences applying a new constitutive model to analyse the springback behaviour of titanium in bending and roll forming. Int J Mech Sci 128-129:389-400. https://doi.org/10.1016/j. ijmecsci.2017.05.025

5. Maeda T, Noma N, Kuwabara T, Barlat F, Korkolis YP (2017) Experimental verification of the tension-compression asymmetry of the flow stresses of a high strength steel sheet. In Procedia Eng 207:1976-1981. https://doi.org/10.1016/j.proeng.2017.10.1099

6. Boers SHA, Geers MGD, Kouznetsova VG (2010) Contactless and frictionless pure bending. Exp Mech 50(6):683-693. https://doi. org/10.1007/s11340-009-9257-2

7. Kim YJ, Lee CH, Kim JH, Lim JH (2018) Numerical modeling of shape memory alloy plates considering tension/compression asymmetry and its verification under pure bending. Int J Solids Struct 136-137:77-88. https://doi.org/10.1016/j.ijsolstr.2017.12.004

8. Sanchez Vega LR, Hanzon DW (2016) Quantification of large uniaxial Bauschinger effects in sheet metal from pure bending/ unbending tests and interferometer techniques. Int J Mech Sci 118:144-154. https://doi.org/10.1016/j.jimecsci.2016.09.017

9. Denk J, Dallmeier J, Huber O (2018) Four-point-bending device for bending moment controlled cyclic reverse loading on plate materials and its application on AZ31B magnesium sheets. Int J Fatigue 109:49-59. https://doi.org/10.1016/j.ijfatigue.2017.12.011

10. Hoefnagels JPM, Buizer CA, Geers MGD (2011) A miniaturized contactless pure-bending device for in-situ SEM failure analysis. Exp Appl Mech 6:587-596

11. $\mathrm{Bu} \mathrm{Y,} \mathrm{Gardner} \mathrm{L} \mathrm{(2018)} \mathrm{Local} \mathrm{stability} \mathrm{of} \mathrm{laser-welded} \mathrm{stainless}$ steel I-sections in bending. J Constr Steel Res 148:49-64. https:// doi.org/10.1016/j.jcsr.2018.05.010

12. Hoefnagels J, Ruybalid A, Buizer C (2015) A small-scale, contactless, pure bending device for in-situ testing. Exp Mech 55: 1511-1524. https://doi.org/10.1007/s11340-015-0046-9

13. Elhebeary M, Saif MTA, Exp Mech (2017) Design, simulation, and testing of a novel bending stage for mechanical characterization of 
materials. Exp Mech 57:89-96. https://doi.org/10.1007/s11340016-0195-5

14. Stölken JS, Evans AG (1998) A microbend test method for measuring the plasticity length scale. Acta Mater 46(14):5109-5115. https://doi.org/10.1016/S1359-6454(98)00153-0

15. Guo X, Xiong H, Li H, Xu Y, Ma Z, El-Aty AA et al (2018) Forming characteristics of tube free-bending with small bending radii based on a new spherical connection. Int $\mathrm{J}$ Mach Tools Manuf 133:72-84. https://doi.org/10.1016/j.ijmachtools.2018.05. 005

16. Pijlman HH, Brinkman J, Huetink J, Vegter H (2000) Material modelling of sheet metal by bi-axial loading tests. American Society of Mechanical Engineers, applied mechanics division. AMD. 239:95-115

17. van Riel M, van den Boogaard AH (2007) Stress-strain responses for continuous orthogonal strain path changes with increasing sharpness. Scr Mater 57(5):381-384. https://doi.org/10.1016/j. scriptamat.2007.05.005

18. Geijselaers HJM, Hilkhuijsen P, Bor TC, van den Boogaard AH (2015) Large strain cyclic behavior of metastable austenic stainless steel. Mater Sci Eng A 631:166-172. https://doi.org/10.1016/j. msea.2015.02.047

19. Gutscher G, Wu HC, Ngaile G, Altan T (2004) Determination of flow stress for sheet metal forming using the viscous pressure bulge (VPB) test. J Mater Process Technol 146(1):1-7. https://doi.org/10. 1016/S0924-0136(03)00838-0

20. Mulder J, Vegter H, Aretz H, Keller S, Van Den Boogaard AH (2015) Accurate determination of flow curves using the bulge test with optical measuring systems. J Mater Process Technol 226:169187. https://doi.org/10.1016/j.jmatprotec.2015.06.034

21. Min J, Stoughton TB, Carsley JE, Carlson BE, Lin J, Gao X (2017) Accurate characterization of biaxial stress-strain response of sheet metal from bulge testing. Int J Plast 94:192-213. https://doi.org/10. 1016/j.ijplas.2016.02.005

22. Peirs J, Verleysen P, Degrieck J (2011) Novel technique for static and dynamic shear testing of Ti6Al4V sheet. Exp Mech 52(7):729741. https://doi.org/10.1007/s11340-011-9541-9

23. Rahmaan T, Abedini A, Butcher C, Pathak N, Worswick MJ (2017) Investigation into the shear stress, localization and fracture behaviour of DP600 and AA5182-O sheet metal alloys under elevated strain rates. Int J Impact Eng 108:303-321. https://doi.org/10.1016/ j.ijimpeng.2017.04.006

24. Yin Q, Tekkaya AE, Traphöner H (2015) Determining cyclic flow curves using the in-plane torsion test. CIRP Ann Manuf Technol 64(1):261-264. https://doi.org/10.1016/j.cirp.2015.04.087

25. Capilla G, Hamasaki H, Yoshida F (2017) Determination of uniaxial large-strain work hardening of high-strength steel sheets from in- plane stretch-bending testing. J Mater Process Technol 243:152169. https://doi.org/10.1016/j.jmatprotec.2016.12.002

26. Kreißig R, Benedix U, Görke U, Lindner M (2007) Identification and estimation of constitutive parameters for material laws in elastoplasticity. GAMM-Mitteilungen 30:458-480. https://doi.org/ 10.1002/gamm.200790027

27. Zang SL, Lee MG, Sun L, Kim JH (2014) Measurement of the Bauschinger behavior of sheet metals by three-point bending springback test with pre-strained strips. Int J Plast 59:84-107. https://doi.org/10.1016/j.ijplas.2014.03.015

28. Nadai (1931) Plasticity: A mechanics of the plastic state of matter (English Translation by A. M. Whal), McGraw-Hill Book Co., pp 164, New York-167

29. Mayville RA, Finnie I (1982) Uniaxial stress-strain curves from a bending test. Exp Mech 22(6):197-201. https://doi.org/10.1007/ BF02326357

30. Kato H, Tottori Y, Sasaki K (2013) Four-point bending test of determining stress-strain curves asymmetric between tension and compression. Exp Mech 54(3):489-492. https://doi.org/10.1007/ s11340-013-9791-9

31. Keelar S, Kimchi M. (2018). Advanced high-strength steels application guidelines version 6.0 . p. 2-11 to $2-11$. https://www. worldautosteel.org/projects/advanced-high-strength-steelapplication-guidelines/

32. Ashwell DG (1950) The anticlastic curvature of rectangular beams and plates. J Royal Aeronautical Soc 54(479):708-715. https://doi. org/10.1017/S0368393100116165

33. Marciniak, Z., Duncan, J.L., \& Hu, S.J. (2002). Mechanics of sheet metal forming: 2nd edition, Jordan Hill, Oxford, ButterworthHeinemann, an imprint of Elsevier science. 96-107. https://doi. org/10.1016/B978-0-7506-5300-8.X5000-6

34. Canny J (1986) A computational approach to edge detection. IEEE Trans Pattern Anal Mach Intell PAMI-8(6):679-698. https://doi. org/10.1109/tpami.1986.4767851

35. Gonzalez RC, Woods RE, Eddins SL (2004) Digital image processing using MATLAB. Pearson Prentice Hall, New Jersey

36. Gruben G, Langseth M, Fagerholt E, Hopperstad OS (2016) Lowvelocity impact on high-strength steel sheets: an experimental and numerical study. Int J Impact Eng 88:153-171. https://doi.org/10. 1016/j.ijimpeng.2015.10.001

37. Löbbe C, Hering O, Hiegemann L, Tekkaya A (2016) Setting mechanical properties of high strength steels for rapid hot forming processes. Materials 9(4):229. https://doi.org/10.3390/ma9040229

Publisher's Note Springer Nature remains neutral with regard to jurisdictional claims in published maps and institutional affiliations. 